\title{
Perioperative outcome of elderly versus younger patients undergoing major hepatic or pancreatic surgery
}

\author{
Qiang Lu ${ }^{1-3}$ \\ Jian-Wen $\mathrm{Lu}^{\mathrm{I}-3}$ \\ Zheng $\mathrm{Wu}^{1-3}$ \\ Xue-Min Liu ${ }^{1-3}$ \\ Jian-Hui $\mathrm{Li}^{2-4}$ \\ Jian Dong ${ }^{1-3}$ \\ Guo-Zhi Yin' \\ Yi Lv'-3 \\ Xu-Feng Zhang ${ }^{1-3}$ \\ 'Department of Hepatobiliary Surgery, \\ The First Affiliated Hospital of Xi'an \\ Jiaotong University, Xi'an, Shaanxi, \\ China; ${ }^{2}$ Institute of Advanced Surgical \\ Technology and Engineering, The First \\ Affiliated Hospital of Xi'an Jiaotong \\ University, Xi'an, Shaanxi, China; \\ ${ }^{3}$ Shaanxi Provincial Regenerative \\ Medicine and Surgical Engineering \\ Research Center, Xi'an, Shaanxi, \\ China; ${ }^{4}$ Department of Surgical \\ Oncology, Shaanxi Provincial People's \\ Hospital, Xi'an, Shaanxi, China
}

This article was published in the following Dove Press journal:

Clinical Interventions in Aging

Objective: The aim of this study was to determine the safety of elderly cancer patients ( $\geq 70$ years) undergoing hepatic resection (HR) or pancreaticoduodenectomy (PD) in comparison with younger adults $(<70$ years).

Methods: A total of 1,012 consecutive patients undergoing HR or PD were included. The incidence and severity of morbidity were documented within 30 days postoperatively and compared between elderly and younger groups. Risk factors associated with postoperative morbidity were investigated by multivariate logistic regression analysis.

Results: Elderly patients ( $\mathrm{n}=111,11.0 \%$ ) had more comorbidities and worse preoperative general condition and liver function versus younger patients $(n=901,89.0 \%)$, and thus were more likely to develop infectious (eg, systemic sepsis and urinary tract infection, both $p<0.01$ ) and technical-associated complications (intraperitoneal bleeding and biliary/pancreatic fistula, $p=0.029$ and $p=0.074$, respectively). However, the incidence and severity of complications were comparable between elderly and younger patients in the whole cohort, and also in HR and PD surgery groups separately. Preoperative hemoglobin (odds ratio [OR] 1.4, $p=0.007$ ) and intraoperative blood transfusion (OR 1.9, $p=0.002$ ), rather than age, were independently associated with postoperative morbidity. Hepatitis (OR 2.9, $p=0.001$ ), preoperative hemoglobin (OR 1.6, $p=0.036$ ), and pancreatic versus hepatic surgery (OR 2.3, $p=0.005$ ) were independently associated with postoperative infectious. For elderly patients only, American Society of Anesthesiologists (ASA) score III (OR 2.1, $p=0.033$ ) and intraoperative blood transfusion (OR 3.2, $p=0.030$ ) were independently associated with postoperative morbidity.

Conclusion: HR and PD can be safely performed in selected elderly patients versus younger patients. Elderly patients with ASA score III or above should be cautiously selected for major surgeries.

Keywords: morbidity, elderly, hepatectomy, pancreaticoduodenectomy

\section{Introduction}

Aging of population is a global phenomenon. For example, according to demographics, older adults are the fastest growing segment of the United States population, and it is expected that there will be a continuous rise in the demand for a variety of surgical services. ${ }^{1}$ In contrast with younger patients, the perioperative management of elderly patients is more complicated because they are more likely to suffer from chronic illnesses such as respiratory disease, cardiovascular disease, diabetes mellitus, and renal dysfunction. ${ }^{2}$ Due to this fragility and decreased physiological reserves, elderly patients are prone to develop postoperative complications and other unexpected outcomes. ${ }^{3-5}$

Correspondence: Xu-Feng Zhang Department of Hepatobiliary Surgery, The First Affiliated Hospital of Xi'an Jiaotong University, 277 West Yanta Road, Xi'an 71006I, Shaanxi, China Tel +862985323626

$\mathrm{Fax}+862985323900$

Email xfzhang125@xjtu.edu.cn

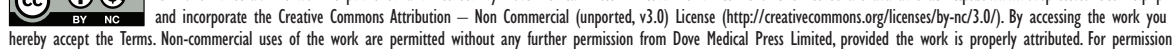
for commercial use of this work, please see paragraphs 4.2 and 5 of our Terms (https://www.dovepress.com/terms.php). 
Elderly patients with liver or pancreas disease are associated with gradual alteration of liver or pancreas structure and function, as well as various changes in hepatic or pancreatic cells including hepatic sinusoidal endothelial cells and pancreatic $\beta$ cells. ${ }^{6-8}$ Surgical resection of the liver or pancreas is a complex procedure with a high rate of morbidity and mortality. ${ }^{9-11}$ Thus, elderly patients underwent surgical treatment less often than younger patients in the past because of the fear of an increased risk of postoperative complications and death. ${ }^{12}$

However, with the development of surgical techniques and perioperative management, some studies with small sample sizes indicated that clinical outcomes of surgical resection for hepatic or pancreatic disease were comparable in younger and elderly patients. ${ }^{10,11,13-19}$ Given these findings, some studies strongly encourage an active approach in elderly patients. ${ }^{11}$ When formulating surgical therapy for elderly patients, surgeons should first focus on the safety of elderly patients, and then balance the net clinical benefit. Thus, the objective of the present study was to evaluate the perioperative outcome of elderly versus younger adults who underwent major hepatic or pancreatic surgery among the 1,012 consecutive cases.

\section{Patients and methods}

\section{Study population and data collection}

All consecutive patients undergoing hepatic resection (HR) or pancreaticoduodenectomy ( $\mathrm{PD}$, Whipple's procedure) for identified hepatic or pancreatic tumors between January 2012 and September 2015 in the authors' institution were retrospectively included based on a prospectively maintained database. The study was approved by the Ethics Committee of The First Affiliated Hospital of Xi' an Jiaotong University. The committee waived the need for written informed consent, since the data were analyzed from electronic medical records and reported without personal identifiers. All the procedures were accomplished by senior surgeons with $>10$ years of hepatopancreatic surgery experience. Patients with one or more of the following conditions were excluded: cachexia, preoperative renal dysfunction, pulmonary or biliary infection, laparoscopic or emergency surgery.

In total, 1,012 patients who underwent HR or PD were classified into two groups according to their age at the time of surgery: elderly ( $\geq 70$ years; $n=111,11.0 \%$ ) and younger patients ( $<70$ years; $n=901,89.0 \%$ ). Data on gender, body mass index, smoking history, comorbidities (eg, cardiac disease, diabetes mellitus, and hepatitis) and American Society of Anesthesiologists (ASA) score were collected from the medical records. Biochemical examination, including blood routine tests and liver function, was routinely performed 24-48 hours prior to the surgery. Surgery duration, intraoperative blood loss and transfusion, and surgical procedures were documented in anesthesia and operation records. The primary disease was evaluated preoperatively and intraoperatively, and confirmed by pathological examination.

\section{Postoperative morbidity}

Postoperative morbidity was evaluated for each patient within 30 days after surgery. Liver failure was defined as a postoperatively acquired deterioration in the ability of the liver to maintain its synthetic, excretory, and detoxifying functions, which are characterized by an increased international normalized ratio and concomitant hyperbilirubinemia on or after postoperative day $5 .{ }^{20}$ Renal failure was defined as an increase in serum creatinine of $\geq 1$. -fold from the preoperative baseline within the first 5 postoperative days. ${ }^{21}$ Biliary fistula was defined as bilirubin levels, in the drain output or in the fluid aspirated from a clinically significant intra-abdominal collection, three times higher than those of serum or confirmed by postoperative radiological examination. Pancreatic fistula was defined as any measurable volume of drain fluid on or after postoperative day 3 with amylase level $>3$ times the upper limit of normal amylase. Intraperitoneal bleeding after HR or PD was defined as a drop in hemoglobin level $>30 \mathrm{~g} / \mathrm{L}$ postoperatively compared with the postoperative baseline level (eg, hemoglobin level immediately after surgery) and/or any postoperative transfusion of packed red blood cells for a falling hemoglobin level and/or the need for invasive re-intervention (eg, embolization or re-laparotomy) to stop bleeding. Pulmonary and peritoneal infection was diagnosed based on clinical symptoms, imaging studies, and/or positive cultures from drainage fluids. Systemic sepsis was confirmed if the patient had at least two of following conditions: 1) body temperature $>38^{\circ} \mathrm{C}$ or $<36^{\circ} \mathrm{C}$; 2) heart rates $>90 \mathrm{bpm}$; 3 ) respiratory rate $>20 / \mathrm{min}$ or $\mathrm{PaCO}_{2}<32 \mathrm{mmHg}$; 4 ) WBC $>12.0 \times 10^{9} / \mathrm{L}$ or $<4.0 \times 10^{9} / \mathrm{L} .{ }^{22}$ Wound infection was defined as infection involving skin, subcutaneous tissue, or deep soft tissues (eg, fascial and muscle layers) of the incision with redness, swelling, tenderness, pain, or purulent drainage with or without laboratory confirmation. Gastric emptying dysfunction was defined as requiring or reinserting a nasogastric tube between day 4 and 14 postoperatively or the inability to tolerate solid diet postoperatively. ${ }^{23}$ Postoperative complication was also classified according to Clavien-Dindo classification of surgical complication. 


\section{Statistical analysis}

Continuous variables were expressed as mean \pm SD or median and compared with the Mann-Whitney $U$ test. Data of categorical variables were expressed as number (percentage) and compared using Pearson's $\chi^{2}$ test. Of all the variables tested in the univariate analysis, only those with $p<0.10$ were enrolled into the multivariate analysis. Logistic regression analysis was performed to evaluate the independent risk factors associated with postoperative complication in all eligible patients or only elderly patients. Odds ratio (OR) and 95\% confidence interval (CI) were calculated. Statistical significance was defined as $p<0.05$. Statistical analysis was performed using SPSS 21.0 (IBM Corporation, Armonk, NY, USA).

\section{Results}

\section{Baseline characteristics}

Among the 1,012 patients, 610 (60.3\%) patients underwent HR, while 402 (39.7\%) patients underwent PD. Not surprisingly, elderly patients had more comorbidities (eg, diabetes and cardiovascular diseases) than younger patients (both $p<0.05$, Table 1$)$. In addition, elderly patients displayed worse preoperative conditions, including higher frequency of Child-Pugh B class, higher ASA score, increased preoperative bilirubin and leukocytes, but decreased albumin and hemoglobin (all $p<0.05$, Table 1). The indications for hepatic and pancreatic surgeries were similar between elderly and younger patients. However, in the included study cohort,

Table I Demographic, operative, and clinical data of younger and elderly patients undergoing hepatectomy and pancreaticoduodenectomy

\begin{tabular}{|c|c|c|c|}
\hline Variables & $\begin{array}{l}\text { Elderly ( } \geq 70 \text { years) } \\
(n=I I I)\end{array}$ & $\begin{array}{l}\text { Younger ( }<70 \text { years) } \\
(\mathrm{n}=90 \mathrm{I})\end{array}$ & $p$-value \\
\hline Gender, male & 81 (73.0\%) & $619(68.7 \%)$ & 0.358 \\
\hline Body mass index & $23.5 \pm 3.6$ & $22.8 \pm 3.2$ & 0.215 \\
\hline Child-Pugh class & & & 0.001 \\
\hline A & $6 \mathrm{I}(55.0 \%)$ & 642 (7I.3\%) & \\
\hline B & $50(45.0 \%)$ & $259(28.7 \%)$ & \\
\hline Smoking history & $36(32.4 \%)$ & 347 (38.5\%) & 0.215 \\
\hline Diabetes & $18(16.2 \%)$ & $76(8.4 \%)$ & 0.014 \\
\hline Cardiovascular disease & $44(39.6 \%)$ & $128(14.2 \%)$ & $<0.001$ \\
\hline ASA score & & & 0.001 \\
\hline I & $5(4.5 \%)$ & $29(3.2 \%)$ & \\
\hline II & $68(61.3 \%)$ & $696(77.2 \%)$ & \\
\hline III & $38(34.2 \%)$ & $176(19.5 \%)$ & \\
\hline Hepatitis B and/or C & $19(17.1 \%)$ & $423(46.9 \%)$ & $<0.001$ \\
\hline Alanine aminotransferase (U/L) & $97.9 \pm 114.8$ & $91.6 \pm 129.8$ & 0.623 \\
\hline Aspartate aminotransferase (U/L) & $92.0 \pm 90.6$ & $82.2 \pm 104.7$ & 0.342 \\
\hline Total bilirubin $(\mu \mathrm{mol} / \mathrm{L})$ & $105.1 \pm 125.7$ & $65.9 \pm 107.4$ & 0.003 \\
\hline Albumin $(g / L)$ & $36.8 \pm 6.5$ & $38.4 \pm 5.2$ & 0.003 \\
\hline White blood cells $\left(\times 10^{9} / L\right)$ & $6.5 \pm 2.6$ & $6.0 \pm 2.7$ & 0.029 \\
\hline Hemoglobin $(g / L)$ & $122.3 \pm 17.6$ & $128.8 \pm 19.4$ & 0.001 \\
\hline Platelet $\left(\times 10^{9} / \mathrm{L}\right)$ & $179.5 \pm 66.3$ & $173.3 \pm 85.9$ & 0.112 \\
\hline Operation time (min) & $268 \pm 64$ & $26 I \pm 83$ & 0.082 \\
\hline Blood loss $(\mathrm{mL})$ & $541.9 \pm 459.4$ & $678.9 \pm 751.1$ & 0.061 \\
\hline Intraoperative transfusion & $46(4 I .4 \%)$ & $413(45.8 \%)$ & 0.419 \\
\hline \multicolumn{4}{|l|}{ Pathological diagnosis } \\
\hline Liver disease & & & 0.166 \\
\hline Hepatocellular carcinoma & 37 (33.3\%) & $479(53.2 \%)$ & \\
\hline Intrahepatic cholangiocarcinoma & $8(7.2 \%)$ & $50(5.5 \%)$ & \\
\hline Metastatic tumors & $4(3.6 \%)$ & $32(3.6 \%)$ & \\
\hline Pancreas disease & & & 0.656 \\
\hline Adenocarcinoma & $58(52.3 \%)$ & $295(32.7 \%)$ & \\
\hline Benign/borderline tumors & $4(3.6 \%)$ & $45(5.0 \%)$ & \\
\hline Surgical procedures & & & $<0.001$ \\
\hline Hepatectomy & 49 (44.1\%) & $56 \mid(62.3 \%)$ & \\
\hline Pancreaticoduodenectomy & $62(55.9 \%)$ & $340(37.7 \%)$ & \\
\hline Types of hepatectomy & & & 0.818 \\
\hline Major hepatectomy & $15(30.6 \%)$ & $163(29.1 \%)$ & \\
\hline Minor hepatectomy & $34(69.4 \%)$ & 398 (70.9\%) & \\
\hline Vascular resection & $4(3.6 \%)$ & $60(6.7 \%)$ & 0.298 \\
\hline
\end{tabular}

Note: Continuous variables are expressed as mean \pm SD and categorical variables as number (percentage). Abbreviation: ASA, American Society of Anesthesiologists. 
Table 2 Postoperative complications in younger and elderly patients

\begin{tabular}{|c|c|c|c|}
\hline Variables & $\begin{array}{l}\text { Elderly } \\
(\geq 70 \text { years) } \\
(n=I I I)\end{array}$ & $\begin{array}{l}\text { Younger } \\
\text { (<70 years) } \\
(n=901)\end{array}$ & $p$-value \\
\hline Peritoneal effusion & $29(26.1 \%)$ & $215(23.9 \%)$ & 0.638 \\
\hline Hydrothorax & $5(4.5 \%)$ & $77(8.5 \%)$ & 0.194 \\
\hline Liver failure & $\mathrm{I}(0.9 \%)$ & 29 (3.2\%) & $0.24 I$ \\
\hline Biliary/pancreatic fistula & $15(13.5 \%)$ & $74(8.2 \%)$ & 0.074 \\
\hline Peritoneal infection & $9(8.1 \%)$ & $59(6.5 \%)$ & 0.545 \\
\hline Pulmonary infection & $8(7.2 \%)$ & 37 (4.1\%) & 0.142 \\
\hline Intraperitoneal bleeding & $9(8.1 \%)$ & $29(3.2 \%)$ & 0.029 \\
\hline Renal failure & $\mathrm{I}(0.9 \%)$ & $4(0.4 \%)$ & 0.517 \\
\hline Systemic sepsis & $17(15.3 \%)$ & $67(7.4 \%)$ & 0.009 \\
\hline Wound infection & $4(3.6 \%)$ & $39(4.3 \%)$ & 1.000 \\
\hline Urinary tract infection & $13(11.7 \%)$ & $32(3.6 \%)$ & $<0.001$ \\
\hline Gastric emptying dysfunction & $4(3.6 \%)$ & $34(3.8 \%)$ & 1.000 \\
\hline Clavien-Dindo classification & & & 0.728 \\
\hline Grade I-II & 37 (33.3\%) & $273(30.3 \%)$ & \\
\hline Grade III-V & II (9.9\%) & $100(11.1 \%)$ & \\
\hline All complications & $48(43.2 \%)$ & $373(41.4 \%)$ & 0.919 \\
\hline In-hospital death & $2(1.8 \%)$ & $7(0.8 \%)$ & 0.278 \\
\hline
\end{tabular}

Note: $p$-values $<0.05$ are shown in bold.

more elderly patients underwent PD, whereas more younger patients underwent HR $(p<0.001$, Table 1).

\section{Postoperative morbidity}

Table 2 shows the comparison of postoperative complications between elderly and younger patients. Roughly, the incidence and severity of postoperative complications were not significantly different between the elderly and younger patients ( $p=0.919$ and $p=0.278$, respectively). Notably, elderly patients were more likely to develop infectious complications (eg, systemic sepsis and urinary tract infection, both $p<0.01$ ) and technical-associated complications (intraperitoneal bleeding and biliary/pancreatic fistula, $p=0.029$ and $p=0.074$, respectively) versus younger patients.

In a separate analysis, elderly patients had similar overall postoperative morbidity compared with younger ones in both hepatic and pancreatic surgery groups (HR group, 51.0\% vs $47.1 \%, p=0.655$; PD group, $37.1 \%$ vs $32.1 \%, p=0.464$; Figure 1A). Moreover, there was no significant difference for severity of the postoperative complications between elderly and younger patients in either HR or PD groups (both $p>0.1$, Figure 1B).

\section{Risk factors associated with postoperative morbidity}

All risk factors with $p<0.1$ identified by univariate analysis were subjected to a stepwise multivariate logistic regression analysis (Table 3). In the multivariate analysis, hemoglobin (OR 1.4, 95\% CI 1.1-2.0, $p=0.007$ ) and intraoperative blood transfusion (OR 1.9, 95\% CI 1.5-2.4, $p=0.002$ ) were independent risk factors of postoperative morbidity across both HR and PD surgery. However, age was not associated with postoperative morbidity in the univariate and multivariate analyses.

\section{Risk factors associated with postoperative infectious complications}

Given that all elderly patients were more likely to develop infectious complications than younger patients, risk factors associated with infectious complication were assessed by univariate and multivariate analyses. In the multivariate analysis (Table 4), hepatitis B or C infection (OR 2.9,
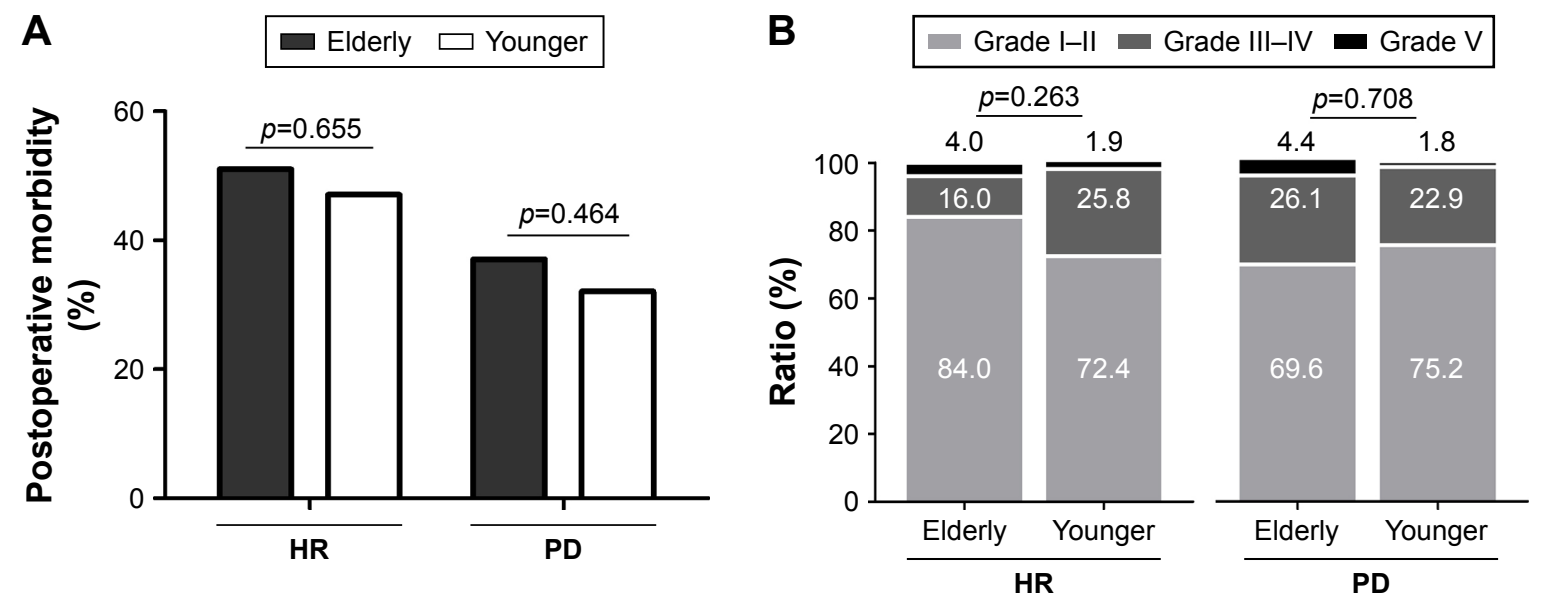

Figure I (A) Overall incidence of postoperative complications following HR or PD in elderly and younger patients. (B) Clavien-Dindo classification of postoperative morbidity in elderly and younger patients who underwent HR or PD.

Abbreviations: HR, hepatic resection; PD, pancreaticoduodenectomy. 
Table 3 Univariate and multivariate analyses of factors associated with morbidity in patients undergoing hepatectomy and pancreaticoduodenectomy in logistic regression model

\begin{tabular}{|c|c|c|c|c|c|}
\hline \multirow[t]{2}{*}{ Factors } & \multirow[t]{2}{*}{ Comparison } & \multicolumn{2}{|c|}{ Univariate analysis } & \multicolumn{2}{|c|}{ Multivariate analysis } \\
\hline & & OR $(95 \% \mathrm{CI})$ & $p$-value & OR (95\% CI) & $p$-value \\
\hline Age (years) & $<70 / \geq 70$ & $1.0(0.7-1.6)$ & 0.849 & & \\
\hline Gender & Male/female & $1.0(0.8-1.3)$ & 0.731 & & \\
\hline Smoking & Yes/no & $1.0(0.8-1.3)$ & 0.963 & & \\
\hline Diabetes & Yes/no & $1.5(1.0-2.2)$ & 0.078 & $1.4(0.9-2.2)$ & 0.150 \\
\hline CVD & Yes/no & $1.2(0.8-1.6)$ & 0.355 & & \\
\hline Hepatitis & Yes/no & $1.7(1.3-1.6)$ & $<0.001$ & $1.2(0.8-1.7)$ & 0.367 \\
\hline \multirow[t]{3}{*}{ ASA score } & I & I & & 1 & \\
\hline & II & $1.6(0.8-3.5)$ & 0.203 & $1.7(0.8-3.7)$ & 0.177 \\
\hline & III & $2.1(1.0-4.7)$ & 0.057 & $2.0(0.9-4.4)$ & 0.104 \\
\hline Child-Pugh class & $\mathrm{B} / \mathrm{A}$ & $1.4(1.0-1.8)$ & 0.035 & $1.0(0.7-1.4)$ & 0.971 \\
\hline Bilirubin $(\mu \mathrm{mol} / \mathrm{L})$ & $>17.1 / \leq 17.1$ & $1.0(0.7-1.2)$ & 0.711 & & \\
\hline Albumin $(g / L)$ & $<30 / \geq 30$ & $1.0(0.6-1.7)$ & 0.907 & & \\
\hline WBC $\left(\times 10^{9} / \mathrm{L}\right)$ & $>10 / \leq 10$ & I.I (0.7-I.7) & 0.766 & & \\
\hline Hemoglobin (g/L) & $<|10| \geq 110$ & $1.4(1.1-2.0)$ & 0.026 & $1.6(1.1-2.2)$ & 0.007 \\
\hline Platelet $\left(\times 10^{9} / \mathrm{L}\right)$ & $<100 \mid \geq 100$ & $1.7(1.3-2.4)$ & 0.001 & $1.3(0.9-1.9)$ & 0.125 \\
\hline Vascular resection & Yes/no & $1.6(1.0-2.7)$ & 0.054 & $1.3(0.8-2.3)$ & 0.276 \\
\hline Surgery type & Liver/pancreas & $1.8(1.4-2.4)$ & $<0.001$ & $1.4(0.9-2.2)$ & 0.119 \\
\hline Blood transfusion & Yes/no & $1.9(1.5-2.4)$ & $<0.001$ & $1.5(1.2-2.0)$ & 0.002 \\
\hline
\end{tabular}

Abbreviations: ASA, American Society of Anesthesiologists; CI, confidence interval; CVD, cardiovascular disease; OR, odds ratio; WBC, white blood cells.

$95 \%$ CI 1.5-5.4, $p=0.001)$, preoperative hemoglobin (OR 1.6, 95\% CI 1.0-2.4, $p=0.036$ ), and pancreatic versus hepatic surgery (OR 2.3, 95\% CI 1.3-4.1, $p=0.005$ ), rather than age, were independently associated with postoperative infectious complications.

\section{Risk factors associated with postoperative morbidity in elderly patients}

A separate analysis was performed to identify risk factors associated with postoperative morbidity of elderly patients. It was found that diabetes, high ASA score, lower hemoglobin,

Table 4 Univariate and multivariate analyses of factors associated with infectious complications of patients undergoing hepatectomy and pancreaticoduodenectomy in logistic regression model

\begin{tabular}{|c|c|c|c|c|c|}
\hline \multirow[t]{2}{*}{ Factors } & \multirow[t]{2}{*}{ Comparison } & \multicolumn{2}{|c|}{ Univariate analysis } & \multicolumn{2}{|c|}{ Multivariate analysis } \\
\hline & & OR (95\% CI) & $p$-value & OR (95\% CI) & $p$-value \\
\hline Age (years) & $<70 / \geq 70$ & I.7 (I.I-2.8) & 0.027 & I.I (0.7-I.9) & 0.680 \\
\hline Gender & Male/female & $0.7(0.5-1.0)$ & 0.054 & I.I (0.7-I.6) & 0.629 \\
\hline Smoking & Yes/no & $0.8(0.6-1.2)$ & 0.299 & & \\
\hline Diabetes & Yes/no & $1.6(0.9-2.7)$ & 0.089 & $1.6(0.9-2.8)$ & 0.122 \\
\hline CVD & Yes/no & $1.4(0.9-2.1)$ & 0.123 & & \\
\hline Hepatitis B or C & Yes/no & $5.8(3.6-9.3)$ & $<0.001$ & $2.9(1.5-5.4)$ & 0.001 \\
\hline \multirow[t]{3}{*}{ ASA score } & I & I & & & \\
\hline & II & $1.9(0.6-6.3)$ & 0.300 & & \\
\hline & III & $2.0(0.6-6.7)$ & 0.291 & & \\
\hline Child-Pugh class & $\mathrm{B} / \mathrm{A}$ & $2.0(1.4-2.8)$ & $<0.001$ & $0.7(0.5-1.2)$ & 0.223 \\
\hline Bilirubin $(\mu \mathrm{mol} / \mathrm{L})$ & $>17.1 / \leq 17.1$ & $1.6(1.1-2.3)$ & 0.006 & I.I (0.7-I.8) & 0.704 \\
\hline Albumin (g/L) & $<30 / \geq 30$ & $1.0(0.4-2.1)$ & 0.916 & & \\
\hline WBC $\left(\times 10^{9} / L\right)$ & $>10 / \leq 10$ & $1.9(1.1-3.3)$ & 0.028 & I.3 (0.7-2.4) & 0.327 \\
\hline Hemoglobin (g/L) & $<\mid 10 / \geq 110$ & $2.2(1.5-3.2)$ & $<0.001$ & $1.6(1.0-2.4)$ & 0.036 \\
\hline Platelet $\left(\times 10^{9} / \mathrm{L}\right)$ & $<100 / \geq 100$ & $2.8(1.6-5.1)$ & 0.001 & $0.8(0.4-1.6)$ & 0.575 \\
\hline Vascular resection & Yes/no & $2.8(1.0-7.9)$ & 0.047 & $\mathrm{I} .8(0.6-5 . \mathrm{I})$ & 0.303 \\
\hline Surgery type & Pancreas/liver & $4.6(3.1-6.6)$ & $<0.001$ & $2.3(1.3-4.1)$ & 0.005 \\
\hline Blood transfusion & Yes/no & $1.7(1.2-2.5)$ & 0.003 & $1.0(0.6-1.5)$ & 0.886 \\
\hline
\end{tabular}

Abbreviations: ASA, American Society of Anesthesiologists; Cl, confidence interval; CVD, cardiovascular disease; OR, odds ratio; WBC, white blood cells. 
Table 5 Univariate and multivariate analyses of factors associated with morbidity in elderly patients undergoing hepatectomy and pancreaticoduodenectomy in logistic regression model

\begin{tabular}{|c|c|c|c|c|c|}
\hline \multirow[t]{2}{*}{ Factors } & \multirow[t]{2}{*}{ Comparison } & \multicolumn{2}{|c|}{ Univariate analysis } & \multicolumn{2}{|c|}{ Multivariate analysis } \\
\hline & & OR $(95 \% \mathrm{Cl})$ & $p$-value & OR $(95 \% \mathrm{CI})$ & $p$-value \\
\hline Gender & Male/female & $2.1(0.8-5.0)$ & 0.113 & & \\
\hline Smoking & Yes/no & $0.8(0.4-1.8)$ & 0.610 & & \\
\hline Diabetes & Yes/no & $4.5(1.5-13.8)$ & 0.008 & $2.0(0.6-7.3)$ & 0.287 \\
\hline CVD & Yes/no & $1.4(0.7-3.1)$ & 0.353 & & \\
\hline Hepatitis & Yes/no & $1.7(0.6-4.5)$ & 0.322 & & \\
\hline ASA score & III/I-II & $2.1(1.4-3.2)$ & $<0.001$ & I.7 (I.0-2.6) & 0.033 \\
\hline Child-Pugh class & $\mathrm{B} / \mathrm{A}$ & $0.6(0.3-1.3)$ & 0.222 & & \\
\hline Bilirubin $(\mu \mathrm{mol} / \mathrm{L})$ & $>17.1 / \leq 17.1$ & $0.7(0.3-1.4)$ & 0.295 & & \\
\hline Albumin $(g / L)$ & $<30 / \geq 30$ & I.8 $(0.5-7.0)$ & 0.408 & & \\
\hline WBC $\left(\times 10^{9} / L\right)$ & $>10 / \leq 10$ & $1.7(0.5-6.0)$ & 0.392 & & \\
\hline Hemoglobin $(g / L)$ & $<|10| \geq \mid 10$ & $3.3(1.4-7.8)$ & 0.008 & $2.2(0.8-5.9)$ & 0.109 \\
\hline Platelet $\left(\times 10^{9} / \mathrm{L}\right)$ & $<|00| \geq 100$ & $3.0(0.7-12.6)$ & 0.138 & & \\
\hline Vascular resection & Yes/no & $1.4(0.3-4.4)$ & 0.489 & & \\
\hline Surgery type & Liver/pancreas & $1.9(0.9-4.1)$ & 0.102 & & \\
\hline Blood transfusion & Yes/no & $3.2(1.5-7.0)$ & 0.004 & $2.6(1.1-6.0)$ & 0.030 \\
\hline
\end{tabular}

Abbreviations: ASA, American Society of Anesthesiologists; Cl, confidence interval; CVD, cardiovascular disease; OR, odds ratio; WBC, white blood cells.

and intraoperative blood transfusion were associated with postoperative complications in the univariate analysis (Table 5). In the multivariate analysis, ASA score (OR 2.1, $95 \%$ CI 1.4-3.2, $p=0.033$ ) and intraoperative blood transfusion (OR 3.2, 95\% CI 1.5-7.0, $p=0.030$ ) were independently associated with postoperative morbidity in the elderly patients.

\section{Discussion}

As life expectancy prolongs, more and more elderly patients are treated in clinics. ${ }^{24}$ Aging is associated with a progressive reduction in the functional reserve of multiple organ systems, increased disability rates, and reduced tolerance of physical, emotional, and social stress; therefore, treatment of elderly patients remains a challenge worldwide. ${ }^{24,25}$ One of the concerns that surgeons and family members face is the safety of elderly patients undergoing surgical procedures. Compared with younger patients, elderly individuals can be considered clinically "fragile" due to their lifetime accumulation of different diseases. ${ }^{5,26}$ However, with the development of surgical techniques and perioperative management, the proportion of elderly patients undergoing surgical procedure is increasing. ${ }^{27}$

Consistent with several previous studies, ${ }^{14,28}$ the present study with a larger sample size demonstrated that elderly patients had a comparable risk of postoperative complication and in-hospital death to younger patients after two major abdominal surgeries, HR and PD. In addition to this, univariate and multivariate analyses indicated that age was not associated with morbidity in patients undergoing major hepatic or pancreatic surgery. Thus, HR and PD were justified for hepatic or pancreatic diseases in selected patients $>70$ years of age.

However, it should be noted that elderly patients undergoing HR or PD were likely to develop infectious complications (eg, urinary tract infection, systemic sepsis) than younger patients. Elderly patients may have diminished immune function, which makes them prone to infectious complications. ${ }^{29-31}$ Urinary tract infection, which is more common in elderly patients, is almost always caused by prolonged catheterization. ${ }^{32,33}$ Elderly patients are more likely to be catheterized because of medication side effects, preexisting incontinence, and decreased mobility, which impedes toileting. ${ }^{34,35}$ In addition, the incidence of intraperitoneal bleeding was higher in elderly patients after HR and PD. It has been manifested that aging decreases the regenerative ability of liver and recovery of hematopoietic function after surgical blood loss, which significantly delays the restoration of coagulation function. ${ }^{36}$

In the multivariate analysis, lower preoperative hemoglobin and intraoperative blood transfusion, rather than age, were strongly associated with increased postoperative complications. Similarly, Tee et al found that preoperative anemia was associated with increased blood transfusion and prolonged time of stay in patients undergoing elective hepatectomy. ${ }^{37}$ Preoperative anemia and intraoperative blood loss may lead to hyoxemia in tissue and organs, which further impedes tissue repair and reconstruction. ${ }^{38}$ Paradoxically, blood transfusion may correct anemia and rescue the life of a patient with massive blood loss, yet it increases postoperative complications. ${ }^{39}$ 
It has been suggested that blood transfusion suppresses the immune system in several ways, including impaired natural killer cell cytotoxicity and lymphocyte activity. ${ }^{40}$ Therefore, perioperative blood transfusion has also been considered to be associated with worse recurrence-free and overall survival in patients with hepatic and pancreatic cancer. ${ }^{39,41-44}$ Of note, in the entire cohort, diabetes, ASA score III, Child-Pugh class $B$, platelet count $<100 \times 10^{9} / \mathrm{L}$, combined major vascular resection, and hepatic versus pancreatic surgery seemed to be associated with increased postoperative morbidity in the univariate analysis; however, they were not independently identified in the multivariate analysis. Actually, in surgically selected patients, the general condition, comorbidities, and liver function routinely improved prior to surgery.

Although infectious complications were higher after surgery in elderly patients compared to younger ones, this was likely to be associated with a lower preoperative hemoglobin and higher proportion of pancreatic surgery in elderly group (Tables 1 and 4), rather than age itself. As shown in Table 1, elderly patients had a higher proportion of pancreaticoduodenectomy than younger patients. As shown in Table 4, pancreaticoduodenectomy is a risk factor associated with postoperative infection versus hepatic surgery. Therefore, increased postoperative infection in elderly patients might be associated with lower preoperative hemoglobin and higher proportion of PD surgery. In fact, we included only one type of pancreatic surgery - pancreaticoduodenectomy. Consistently, Kim et al demonstrated that older patients undergoing $\mathrm{HR}$ for liver cancer were more likely to develop postoperative pneumonia versus younger patients, and yet had a similar incidence of postoperative complications and mortality with younger ones. ${ }^{45}$ Not surprisingly, lower hemoglobin or preoperative anemia is an established risk factor for mortality and morbidity in elective surgeries. ${ }^{46}$ Infectious disease is the main cause of postoperative complications, which occurred in one-third of patients undergoing PD. ${ }^{47}$ However, postoperative infection is not that common in patients undergoing HR, with the reported incidence ranging from $3.3 \%$ to $17.0 \% .{ }^{48-50}$ Interestingly, hepatitis, although being less common in elderly versus younger patients, increased postoperative infection. Hepatitis $\mathrm{B}$ or $\mathrm{C}$ virus has been shown to impair not only hepatic function, but also the immune system of the whole body, and is therefore associated with increased infectious complications after major surgeries or in critically ill patients. ${ }^{47,51}$ In the univariate analysis, patients with compromised liver function, higher preoperative bilirubin and white blood cells, lower platelets, and combined vascular invasion and intraoperative blood transfusion seemed to be more likely to develop infections. In contrast, these factors were excluded in our multivariate analysis, indicating their confounding or weak contributions to postoperative morbidity.

In elderly patients undergoing hepatic and pancreatic surgery, ASA score and intraoperative blood transfusion were independent risk factors associated with postoperative complications. It has been found that a high ASA score was significantly associated with postoperative morbidity and mortality among patients undergoing major gastrointestinal surgery. ${ }^{19,52}$ Aging is combined with a gradual decline in the blood flow, volume, and function of the liver and pancreas. Also, elderly patients tended to have other comorbidities prior to surgery. Thus, elderly patients with ASA score III should be cautiously selected for surgery. Moreover, preoperative correction of anemia, minimization of intraoperative blood loss, and strict control of intraoperative blood transfusion should be emphasized especially in elderly patients. ${ }^{52}$ Of note, combined major vascular resection in hepatic or pancreatic surgery was not associated with postoperative morbidity among the whole cohort and elderly patients. The findings indicate the safety of extended surgery even in elderly patients, with potential benefits in improving the long-term survival of patients. ${ }^{28}$

\section{Limitations}

There are several limitations of the present study. First, this is a retrospective study, thus an inherent selection bias cannot be excluded. For example, elderly patients must have been more strictly selected for hepatic and pancreatic surgery after careful evaluation of the functions of vital organs, making them being more like "younger". The discrepancy of the morbidity incidence and risk factors associated may complicate the results. However, the incidence and severity of postoperative morbidity were consistently comparable between elderly and younger patients in either hepatic or pancreatic surgery, and age was not associated with overall morbidity in the multivariate analysis when adjusted for other potential confounding factors.

\section{Conclusion}

In summary, elderly patients were more likely to develop infectious complications than younger ones, probably as a result of lower preoperative hemoglobin and higher proportion of pancreatic surgery included in the current study. The incidence and severity of complications were comparable between elderly and younger patients in the whole cohort, and also in HR or PD surgery groups separately. Therefore, both HR and PD can be safely performed in selected elderly patients. 


\section{Acknowledgments}

This study was supported in part by the National Natural Science Foundation of China (81372582), "New-Star" Young Scientists in Shaanxi Provincial Program (2014kjxx-30), the Science and Technology Innovative Research Team of Shaanxi Province (2014KCT-24), and the Clinical Research Award of the First Affiliated Hospital of Xi'an Jiaotong University, China (XJTU1AF-CRF-2017-004 and XJTU1AF-CRF-2015-018). The sponsors had no role in the study design, performance, or data explanation.

\section{Disclosure}

The authors report no conflicts of interest in this work.

\section{References}

1. Dall TM, Gallo PD, Chakrabarti R, West T, Semilla AP, Storm MV. An aging population and growing disease burden will require a large and specialized health care workforce by 2025. Health Aff. 2013; 32(11):2013-2020.

2. Beliveau MM, Multach M. Perioperative care for the elderly patient. Med Clin North Am. 2003;87(1):273-289.

3. Piccirillo JF, Tierney RM, Costas I, Grove L, Spitznagel EL. Prognostic importance of comorbidity in a hospital-based cancer registry. JAMA. 2004;291(20):2441-2447.

4. Lemmens VEPP, Janssen-Heijnen MLG, Verheij CDGW, Houterman S, Repelaer van Driel OJ, Coebergh JWW. Co-morbidity leads to altered treatment and worse survival of elderly patients with colorectal cancer. Br J Surg. 2005;92(5):615-623.

5. Shahir MA, Lemmens VEPP, van de Poll-Franse LV, Voogd AC, Martijn H, Janssen-Heijnen MLG. Elderly patients with rectal cancer have a higher risk of treatment-related complications and a poorer prognosis than younger patients: a population-based study. Eur J Cancer. 2006;42(17):3015-3021.

6. Kim IH, Kisseleva T, Brenner DA. Aging and liver disease. Curr Opin Gastroenterol. 2015;31(3):184-191.

7. Chantarojanasiri T, Hirooka Y, Ratanachu-ek T, Kawashima H, Ohno E, Goto H. Evolution of pancreas in aging: degenerative variation or early changes of disease? J Med Ultrason. 2014;42(2):177-183.

8. Saisho Y, Butler AE, Meier JJ, et al. Pancreas volumes in humans from birth to age one hundred taking into account sex, obesity, and presence of type-2 diabetes. Clin Anat. 2007;20(8):933-942.

9. Wang H-Q. Liver resection in hepatitis B-related hepatocellular carcinoma: clinical outcomes and safety in elderly patients. World $J$ Gastroenterol. 2014;20(21):6620-6625.

10. Higuera O. Management of pancreatic cancer in the elderly. World $J$ Gastroenterol. 2016;22(2):764-775.

11. van der Geest LGM, Besselink MGH, van Gestel YRBM, et al. Pancreatic cancer surgery in elderly patients: balancing between short-term harm and long-term benefit. A population-based study in the Netherlands. Acta Oncol. 2015;55(3):278-285.

12. Partridge JSL, Harari D, Dhesi JK. Frailty in the older surgical patient: a review. Age Ageing. 2012;41(2):142-147.

13. Su C-W, Lei HJ, Chau GY, et al. The effect of age on the long-term prognosis of patients with hepatocellular carcinoma after resection surgery. Arch Surg. 2012;147(2):137-144.

14. Kow AW, Kwon CH, Song S, Kim JM, Joh JW. Clinicopathological factors and long-term outcome comparing between lung and peritoneal metastasectomy after hepatectomy for hepatocellular carcinoma in a tertiary institution. Surgery. 2015;157(4):645-653.

15. Nozawa A, Kubo S, Takemura S, et al. Hepatic resection for hepatocellular carcinoma in super-elderly patients aged 80 years and older in the first decade of the 21st century. Surg Today. 2014;45(7):851-857.
16. Lee SH, Choi HC, Jeong S-H, et al. Hepatocellular carcinoma in older adults: clinical features, treatments, and survival. J Am Geriatr Soc. 2011;59(2):241-250.

17. Borzio M, Dionigi E, Vitale A, et al. Management and prognosis of hepatocellular carcinoma in the elderly: results of an in-field multicenter cohort study. Liver Int. 2017;37(8):1184-1192.

18. Frakes JM, Strom T, Springett GM, et al. Resected pancreatic cancer outcomes in the elderly. J Geriatr Oncol. 2015;6(2):127-132.

19. Marsoner K, Kornprat P, Sodeck G, et al. Pancreas cancer surgery in octogenarians - should we or should we not? Anticancer Res. 2016;36(4): 1979-1984.

20. Kauffmann R, Fong Y. Post-hepatectomy liver failure. Hepatobiliary Surg Nutr. 2014;3(5):238-246.

21. Bellomo R, Ronco C, Kellum JA, Mehta RL, Palevsky P. Acute renal failure - definition, outcome measures, animal models, fluid therapy and information technology needs: the Second International Consensus Conference of the Acute Dialysis Quality Initiative (ADQI) Group. Crit Care. 2004;8(4):R204-R212.

22. Singer M, Deutschman CS, Seymour CW, et al. The Third International Consensus definitions for sepsis and septic shock (sepsis-3). JAMA. 2016;315(8):801-810.

23. Welsch T, Borm M, Degrate L, Hinz U, Büchler MW, Wente MN. Evaluation of the International Study Group of Pancreatic Surgery definition of delayed gastric emptying after pancreatoduodenectomy in a high-volume centre. Br J Surg. 2010;97(7):1043-1050.

24. Balducci L, Extermann M. Management of cancer in the older person: a practical approach. Oncologist. 2000;5(3):224-237.

25. Repetto L, Fratino L, Audisio RA, et al. Comprehensive geriatric assessment adds information to Eastern Cooperative Oncology Group performance status in elderly cancer patients: an Italian Group for Geriatric Oncology Study. J Clin Oncol. 2002;20(2):494-502.

26. Robinson TN, Wallace JI, Wu DS, et al. Accumulated frailty characteristics predict postoperative discharge institutionalization in the geriatric patient. J Am Coll Surg. 2011;213(1):37-42.

27. Pofahl WE, Pories AJ. Current status and future directions of geriatric general surgery. J Am Geriatr Soc. 2003;51(7 Suppl):S351-S354.

28. Kanda M, Fujii T, Suenaga M, et al. Pancreatoduodenectomy with portal vein resection is feasible and potentially beneficial for elderly patients with pancreatic cancer. Pancreas. 2014;43(6):951-958.

29. Hakim FT, Flomerfelt FA, Boyiadzis M, Gress RE. Aging, immunity and cancer. Curr Opin Immunol. 2004;16(2):151-156.

30. Montecino-Rodriguez E, Berent-Maoz B, Dorshkind K. Causes, consequences, and reversal of immune system aging. J Clin Invest. 2013; 123(3):958-965.

31. Pfister G, Savino W. Can the immune system still be efficient in the elderly? An immunological and immunoendocrine therapeutic perspective. Neuroimmunomodulation. 2008;15(4-6):351-364.

32. Rowe TA, Juthani-Mehta M. Diagnosis and management of urinary tract infection in older adults. Infect Dis Clin North Am. 2014;28(1):75-89.

33. Matthews SJ, Lancaster JW. Urinary tract infections in the elderly population. Am J Geriatr Pharmacother. 2011;9(5):286-309.

34. Tenke P, Köves B, Johansen TEB. An update on prevention and treatment of catheter-associated urinary tract infections. Curr Opin Infect Dis. 2014;27(1):102-107.

35. Tambyah PA, Oon J. Catheter-associated urinary tract infection. Curr Opin Infect Dis. 2012;25(4):365-370.

36. Kim IH, Kisseleva T, Brenner DA. Aging and liver disease. Curr Opin Gastroenterol. 2015;31(3):184-191.

37. Tee MC, Shubert CR, Ubl DS, Habermann EB, Nagorney DM, Que FG. Preoperative anemia is associated with increased use of hospital resources in patients undergoing elective hepatectomy. Surgery. 2015; 158(4):1027-1038.

38. Tohme S, Varley PR, Landsittel DP, Chidi AP, Tsung A. Preoperative anemia and postoperative outcomes after hepatectomy. HPB. 2016; 18(3):255-261.

39. Liu L, Wang Z, Jiang S, et al. Perioperative allogenenic blood transfusion is associated with worse clinical outcomes for hepatocellular carcinoma: a meta-analysis. PLoS One. 2013;8(5):1-10. 
40. Kaplan J, Sarnaik S, Gitlin J, Lusher J. Diminished helper/suppressor lymphocyte ratios and natural killer activity in recipients of repeated blood transfusions. Blood. 1984;64(1):308-310.

41. Ross A, Mohammed S, VanBuren G, et al. An assessment of the necessity of transfusion during pancreatoduodenectomy. Surgery. 2013;154(3):504-511.

42. Kooby DA, Stockman J, Ben-Porat L, et al. Influence of transfusions on perioperative and long-term outcome in patients following hepatic resection for colorectal metastases. Ann Surg. 2003;237(6): 860-870.

43. Kimura N, Toyoki Y, Ishido K, et al. Perioperative blood transfusion as a poor prognostic factor after aggressive surgical resection for hilar cholangiocarcinoma. J Gastrointest Surg. 2015;19(5):866-879.

44. Sima CS, Jarnagin WR, Fong Y, et al. Predicting the risk of perioperative transfusion for patients undergoing elective hepatectomy. Ann Surg. 2009;250(6):914-921.

45. Kim JM, Cho BI, Kwon CH, et al. Hepatectomy is a reasonable option for older patients with hepatocellular carcinoma. Am J Surg. 2015;209(2):391-397.

46. Miceli A, Romeo F, Glauber M, de Siena PM, Caputo M, Angelini GD. Preoperative anemia increases mortality and postoperative morbidity after cardiac surgery. J Cardiothorac Surg. 2014;9:137.
47. Okano K, Hirao T, Unno M, et al. Postoperative infectious complications after pancreatic resection. Br J Surg. 2015;102(12):1551-1560.

48. Hirokawa F, Hayashi M, Miyamoto Y, et al. Evaluation of postoperative antibiotic prophylaxis after liver resection: a randomized controlled trial. Am J Surg. 2013;206(1):8-15.

49. Garwood RA, Sawyer RG, Thompson L, Adams RB. Infectious complications after hepatic resection. Am Surg. 2004;70(9):787-792.

50. Moreno Elola-Olaso A, Davenport DL, Hundley JC, Daily MF, Gedaly R. Predictors of surgical site infection after liver resection: a multicentre analysis using National Surgical Quality Improvement Program data. HPB. 2012;14(2):136-141.

51. Kueht M, Bebko S, Helmick R, Awad S. Hepatitis C status and infectious complications in the surgical intensive care unit: a retrospective analysis of 1,941 consecutive patients. Am J Surg. 2016;211(6):1064-1070.

52. Cerullo M, Gani F, Chen SY, et al. Physiologic correlates of intraoperative blood transfusion among patients undergoing major gastrointestinal operations. Surgery. 2017;162(2):211-222.
Clinical Interventions in Aging

\section{Publish your work in this journal}

Clinical Interventions in Aging is an international, peer-reviewed journal focusing on evidence-based reports on the value or lack thereof of treatments intended to prevent or delay the onset of maladaptive correlates of aging in human beings. This journal is indexed on PubMed Central, MedLine,

\section{Dovepress}

CAS, Scopus and the Elsevier Bibliographic databases. The manuscript management system is completely online and includes a very quick and fair peer-review system, which is all easy to use. Visit http://www.dovepress. com/testimonials.php to read real quotes from published authors. 